\title{
Cerimonial e protocolo na defesa de monografia dos cursos de graduação: um rito de passagem
}

\section{Cerimonial and protocol on the defense of monographs for undergraduation courses: a rite of passage}

\author{
José Solon Sales e Silva (SILVA, J. S. S.) ${ }^{*}$
}

RESUMO: Discorre sobre a apresentação da monografia de graduação, como rito de passagem e discute o significado da defesa da monografia nos cursos de graduação, partindo-se desta vivência no Curso de Turismo da Universidade de Fortaleza. Apresenta revisão teórica sobre as funções do cerimonial e protocolo e sua utilização na vida acadêmica e os ritos de passagem, para o aluno concluinte. Objetiva identificar a relevância deste rito de passagem para a comunidade acadêmica. A metodologia utilizada foi a pesquisa participante, que é iniciada na realidade concreta, tendo o estudo se desenvolvido dentro do próprio grupo de professores e alunos envolvidos com a disciplina. Caracteriza-se a defesa de monografia como rito intermediário de passagem para $\mathrm{o}$ ato de colação de grau, por ser este o rito de passagem da vida acadêmica para a vida profissional. Propôs-se, com base na revisão bibliográfica e no estudo de campo, um roteiro de cerimonial e protocolo para defesas de monografias nos cursos de graduação.

Palavras-chave: Antropologia cultural; rito de passagem; cerimonial e protocolo.

ABSTRACT: Analyzes undergraduate final work presentations, as a graduation ritual, and discusses the meaning of these presentations using the experience of the tourism undergraduate students at the University of Fortaleza. It presents a theory review about the ceremonial functioning and protocol and their uses in academic life and how it can be used to understand the passage ritual for the student that is about to graduated. The main objective is to identify how important this passage ritual is for the academic community. The methodology used was a participant's research, taking real experience as support, considering professors and students in a same discipline in the tourism course. The final defense presentation is characterized as an intermediate passage ritual for the graduation ceremony, since it represents a step from academic to professional life. Intends, using the bibliography review and the field research, to create a ceremonial guidebook and protocol to base final work presentations of undergraduate courses.

Keywords: Cultural anthropology, passage ritual, ceremonial and protocol.

\footnotetext{
* Bacharel em Direito pela Universidade de Fortaleza, 1982. Especialista em Turismo pela Universidade de Fortaleza - UNIFOR, 1988. Mestre em Gestão de Negócios Turísticos pela Universidade Estadual do Ceará, 2002. Professor do Curso de Turismo e Turismo e Hotelaria da UNIFOR. Professor e Coordenador dos Cursos de Turismo e Hospitalidade do Centro Federal de Educação Tecnológica do Ceará. Endereços: Rua Vilebaldo Aguiar, 1580 (Ap. 403), Coco, Fortaleza - Ceará - CEP: 60.190-780. Telefones: (85) 3234-2338 e (85) 8746-6062 - Fax: (85) 3477-30-65.E-mail: solon@ unifor.br ou solon@ cefetce.br
} 


\section{INTRODUÇÃO}

O homem ocupa um e único lugar em termos de ambiência e se distingue na escala zoológica. Desde os pequenos grupos errantes de trogloditas aos mais complexos grupos humanos da modernidade, encontra-se em todos eles, rituais simbólicos para os mais diversos momentos da vida. Integram estes ritos o cerimonial e protocolo, assuntos afetos à Antropologia Cultural.

Entender as funções do cerimonial e protocolo e seu papel na sociedade hodierna foi uma constante preocupação ao longo do estudo. Em meio a estas funções aparecem os ritos de passagem que eclodem nos mais diversos momentos, entremeados de várias simbologias. Como rito de passagem defendeu-se que a defesa de monografia nos cursos de graduação integra um momento onde o aluno culmina a vida acadêmica, constituindo-se este ato em elemento de transição entre o término da graduação e a colação de grau.

Encontrar a relevância deste rito de passagem para a comunidade acadêmica foi a preocupação deste estudo. A investigação desenvolvida por meio da pesquisa participante contemplou os protagonistas envolvidos neste ato, quais sejam professores e alunos ligados à disciplina de Monografia II, da matriz curricular do Curso de Turismo e Hotelaria da Universidade de Fortaleza.

\section{FUNÇÕES DO CERIMONIAL E PROTOCOLO}

Diferentemente do que possa parecer, o cerimonial integra a vida humana desde tempos memoriais, pois registros mostram que já no período neolítico, ainda em sociedades ágrafas as cerimônias já aconteciam e, ao longo da evolução histórica da própria sociedade estas foram se aperfeiçoado e chegaram até os dias atuais.

Conforme Viana (1998, p. 17)

(...) o cerimonial é um conjunto de formalidades específicas de um ato público, dispostas numa ordem seqüencial, que envolve a utilização de indumentária própria, a ordem de precedência a ser observada, com seus elementos sígnicos e o cumprimento de um ritual. 
Conceito complexo, envolvendo, sobretudo, muitos elementos sígnicos, o cerimonial divide-se em público e privado, aquele ligado ao Poder Público compreendendo o cerimonial da Presidência da República; cerimonial Civil e Militar e cerimonial dos Estados e Municípios; enquanto o segundo diz respeito aos atos e acontecimentos afetos ao setor privado regidos pelas normas consuetudinárias, aliados a base legal do Cerimonial Público que tem sua sustentação jurídica regulamentada pelo Decreto Federal no 70.724 de 09 de março de 1972. Desta forma encontra-se o Cerimonial Universitário que ocupa lugar no Cerimonial Privado podendo ser também por normas internas de cada Universidade. (SILVA, 2005)

Relativamente ao protocolo que também integra os atos, é este o registro dos atos públicos. Tal registro faz-se por meio de documentos sempre presentes em qualquer ato. Em sentido figurado o protocolo designa formalidades ligadas à etiqueta social e que servem de pré-requisito para participação num ato público.

Aliado ao binômio Cerimonial e Protocolo é indispensável lembrar-se da etiqueta, por ser esta a base para os demais. Enquanto o Cerimonial e Protocolo constituem requisitos do anfitrião a etiqueta é prerrogativa do convidado, razão porque se faz necessário o conhecimento individual da etiqueta para saber como portar-se e conduzir-se nas cerimônias. Assim, tem-se que o Cerimonial e Protocolo são coletivos, dirigidos pelo anfitrião, enquanto a etiqueta é individual, prerrogativa do convidado. (SILVA, 2005).

O Cerimonial preenche várias funções em um ato, distinguindo-se a função ritual; a semiológica; a legislativa; a pedagógica e por fim a gratuita. Dentre estas a função mais relevante é a ritual por ser ela a que traduz os gestos, privilégios e símbolos de poder incluindo-se aqui o disciplinamento das precedências. Relativamente à função semiológica têm-se nesta, a linguagem formal a ser utilizada com suas formas de tratamento e de cortesia além da redação e expressões próprias de cada ato.

Codificar as regras e preceitos em normas referentes ao cerimonial e, sobretudo ao protocolo é o papel da função legislativa, enquanto que a pedagógica aborda os aspectos que se relacionam à cultura de determinado povo. Por fim a função gratuita trata do festejo propriamente dito por ser este lúdico e propiciar prazer aos envolvidos no ato, notadamente o anfitrião. Estas condições são essenciais ao futuro profissional para qualquer momento e em qualquer área de atuação. 


\section{DEFESA DE MONOGRAFIA NOS CURSOS DE GRADUAÇÃO: UM RITO DE PASSAGEM PARA A COLAÇÃO DE GRAU}

A sociedade medieval cria, no século XI, as primeiras Universidades. Dentre elas destacam-se os seguintes anos de criação: em 1158 na Bolonha; 1170 em Paris, que a partir de 1180 passa a ser designada Universidade de Sorbone; 1218 em Salamanca; 1222 em Pádua; 1224 em Nápoles e 1290 em Coimbra. Segundo Viana (1998) “a Universidade de Coimbra (Portugal), onde se desenvolveu o mais escorreito cerimonial europeu foi, pois o local indicado para as universidades brasileiras buscarem o seu modelo". Desta sorte herdaram o cerimonial adotado, notadamente aqueles relativos ao ritual dos atos acadêmicos desta secular universidade. (VIANA, 1998, p. 43)

De acordo com Velloso (2001, p. 34) "o papel da universidade, ao longo do tempo, foi e tem sido o de promover a educação superior e o desenvolvimento científico, tecnológico, literário, artístico, cultural e social do país e da humanidade." A cultura vem formando através dos tempos os mais diversos ritos para engrandecer e enaltecer o significado das mais variadas etapas da vida humana.

Entendendo-se por rito o ato ou conjunto de comportamentos que segue certas regras que se repetem ao longo da história, sendo estes atos individuais ou coletivos encontram-se na vida universitária vários deles, que irão culminar com o rito da colação de grau, o último ato da vida acadêmica. Conforme Kacelnik (1974, p. 79) ritos de passagem são aqueles "que acompanham a passagem do indivíduo de um grupo a outro, de um status a outro, na infância, puberdade e vida adulta." Como processo de ritual no campo da academia, é conveniente lembrar do rito de entrada no ensino superior por que passa o chamado "calouro" quando é submetido a um trote, logo após o início do ingresso na vida acadêmica. O segundo ato realizado por meios de uma ritualística é a defesa de monografia.

No atinente a tipologia dos ritos, de acordo com a finalidade perseguida, estes admitem grande variedade de tipos, dentre eles, Kacelnik (1974, p. 18) destaca: os ritos imitativos; os positivos e negativos; os de sacrifícios; os ritos de passagem; os de fortalecimento e aqueles relacionados com os alimentos. Para o estudo proposto interessam tão somente os ritos de passagem por serem estes os que marcam a passagem de um estado social a outro, podendo ter como centro o indivíduo, como o nascimento, 
a puberdade, matrimônio, funerais, iniciação, que é exatamente a defesa da monografia, de vez que este ato coroa o término da vida acadêmica e prepara o acadêmico para o rito da colação de grau, que habilita, enfim, ao neo-graduando ingressar na vida profissional.

Para a vida acadêmica o prêmio pelo esforço, empenho e dedicação ao longo de quatro ou cinco anos de estudos avançados no curso superior culminam com o rito da colação de grau. Entretanto para chegar a esta fase o acadêmico passa por um ritual no âmbito do curso que traduz a exposição para a comunidade acadêmica, do conhecimento adquirido ao longo dos anos de graduação.

A produção de um trabalho monográfico concentra a solidificação de todo o estudo realizado. Neste trabalho o aluno congrega o estudo desenvolvido nas disciplinas de formação básica e técnica, através da revisão literária do seu tema de estudo aliado aos métodos e técnicas de pesquisa, consolidando e impulsionando a evolução do conhecimento.

A monografia é apresentada em um rito acadêmico denominado "Defesa de Monografia”, quando o aluno defende e comprova a pesquisa realizada perante a comunidade acadêmica. Traduzindo o coroamento do próprio conhecimento adquirido, este momento deve ser realizado com toda a pompa e circunstância que o ato merece, pois, traduz, reitera-se a sagração do esforço e dedicação ao estudo o que comprova um rito de passagem. O ato de "Defesa de Monografia" deve ser planejado e executado, sobretudo por uma questão de respeito ao aluno.

Ressalte-se que as "Defesas de Dissertações e Doutorados" são cerimônias das mais concorridas, obedecendo a toda a ritualística de cerimonial e protocolo acadêmico que a ocasião comporta. Portanto compete aos Cursos de Graduação treinar seus alunos nesta ritualística para que, aqueles que seguirem em cursos de pós-graduação cheguem ali bem preparados e familiarizados com este processo ritual.

\section{SUGESTÃo DE ROTEIRO CERIMONIALÍSTICO E PROTOCOLAR PARA DEFESA DE MONOGRAFIA}

Constituindo-se a Defesa de Monografia em ato solene, o professor deve conhecer e dominar a ritualística de cerimonial e protocolo para fazer deste momento da 
vida universitária do aluno, um momento de pompa e circunstância. A Coordenação de Curso deverá iniciar com o convite à comunidade acadêmica, para a Defesa. O ambiente deve ser preparado com sobriedade e elegância para receber os convidados. A chamada banca de avaliação deverá postar-se em local de destaque, na sala ou auditório, assim como o aluno avaliado.

A cerimônia é presidida pelo Orientador que neste ato será o Presidente da Defesa. $\mathrm{O}$ ato tem início com a apresentação do aluno e do tema da pesquisa, seguido da apresentação da banca. $\mathrm{O}$ aluno e professores deverão ser anunciados com a leitura dos nomes e sobrenomes, assim como a titulação de cada professor.

Na seqüência o Presidente do ato deverá ler as regras para defesa (estas podem variar de curso para curso) informando a assistência o tempo disponibilizado para a apresentação da pesquisa, bem como o tempo para cada um dos examinadores fazer suas considerações.

Terminada a exposição do aluno a ordem de fala dos examinadores deverá seguir a ordem de precedência: inicialmente o professor doutor, posteriormente o professor mestre. No caso de ambos serem doutores ou mestres segue-se a precedência pelo decanato. Ressalte-se que há ainda o critério da cortesia, quando em bancas mistas existirem um doutor e um mestre (professora) o professor doutor poderá ceder sua vez a colega, usando o critério da cortesia. Esta prerrogativa é individual.

É fundamental e relevante observar que o Orientador não deve tecer comentários a respeito do trabalho, considerando-se que na condição de Orientador ele é também um co-autor, e a banca irá avaliar não só o aluno, mas também sua orientação.

Compete ao Orientador, após o pronunciamento da banca, tecer alguns comentários breves sobre o processo de orientação realizado ao longo do semestre, sem entrar em questões do mérito, pois esta tarefa é exclusividade da banca. Terminada esta fase da defesa o Presidente deverá solicitar ao aluno e a assistência aguardar o resultado fora da sala. Depois de esvaziada a sala a banca delibera sobre as correções que devem ser realizadas e também sobre a nota.

Concluído este processo, o Presidente convoca o aluno e assistência para tomar conhecimento do resultado. No momento de anunciar o resultado o Presidente, a Banca e o aluno devem postar-se de pé para ouvir a leitura da ata de defesa que vai assinada por todos e constitui o protocolo do ato. Concluída a leitura da ata é o momento para a 
banca cumprimentar o aluno, assim como a assistência.

A organização da apresentação por parte do aluno também deverá seguir uma seqüência lógica. Lembrar-se que neste momento não se irá apresentar exclusivamente teorias de vez que estas são a sustentação para comprovação da pesquisa e os examinadores já fizeram a correção exaustiva do estudo. Aqueles que se interessarem pelo tema terão a oportunidade de ler o estudo na íntegra quando o mesmo for disponibilizado pela Coordenação do Curso para empréstimo.

O aluno deverá estruturar sua apresentação incluindo itens como: a) Identificação da IES, do tema, do aluno e do orientador; b) Justificativa do tema; c) Objetivo geral; d) Objetivos específicos; e) Contribuição social do estudo; e) Marco teórico (idéias e autores mais importantes); f) Procedimentos metodológicos; g) Apresentação e análise dos resultados; h) Considerações finais; i) Referências bibliográficas.

\section{MATERIAIS E MÉTODOS}

O referencial que serviu de suporte para este estudo foi a forma como vinha se praticando as defesas de monografia dos alunos do Curso de Turismo da Universidade de Fortaleza, e que ao longo dos semestres sofreu algumas transformações sugeridas pelos próprios professores a partir do semestre 2000.1, quando se implantou uma nova matriz curricular que passou a contemplar a disciplina de monografia. Ofertada pela matriz do Curso, integrantes do sétimo semestre os primeiros alunos a cursar esta disciplina matriculam-se em 2003.1. Nesta fase do curso o professorado não tinha ainda segurança no atinente a "Defesa de Monografia" e o processo aperfeiçoou-se a partir de iniciativa do grupo em, inicialmente realizar um curso para orientação de monografia. Tal atitude se deu com professores do próprio curso, onde aqueles que dominavam determinado assunto ensinavam aos demais colegas, tendo sido montado de forma institucional o curso para obter-se um padrão satisfatório tanto para as orientações como par as avaliações das bancas do Curso de Turismo. Anteriormente a este curso um pequeno grupo de professores formados pelas professoras Ângela Maria Ferreira, Maria de Fátima Aguiar e Norma Lopes Ginez Mota já havia elaborado o manual de orientação metodológica e funcional para a disciplina. 
Competiu-nos passar aos colegas o cerimonial de apresentação das monografias, pelo fato de estudar este tema e ministrar esta disciplina ao longo da prática acadêmica. A metodologia utilizada foi a pesquisa participante.

Por este método a comunidade acadêmica participou da análise de sua própria realidade visando promover uma transformação de melhoria para benefícios dos próprios agentes envolvidos com o processo de defesa de monografia. Tendo este método como característica o processo de conhecimento e ação da população envolvida desenvolvendo um aumento do entendimento e do conhecimento da situação particular, qual seja, o rito de defesa de monografia na graduação, parte-se, a partir daqui para uma ação de mudança em benefício desta comunidade. A pesquisa desenvolveu-se durante os semestres 2006.2 e 2007.1 com os professores envolvidos com a orientação de monografia no Curso de Turismo da Universidade de Fortaleza. Relativamente aos professores, escolhidos aleatoriamente, foram observados os aspectos de formalidade e informalidade na condução do processo de defesa. Quando participou-se do rito houve um envolvimento e familiarização da situação, em outro momento sem participar do rito observou-se a reação do aluno diante da deferência do seu trabalho. Após as defesas, escolhidas aleatoriamente foi feito pesquisa informal com os alunos que haviam defendido o seu trabalho para saber como avaliaram o processo.

\section{RESULTADOS}

Observou-se durante o processo da pesquisa que nos grupos onde o cerimonial e protocolo foram aplicados o ato reverteu-se de maior seriedade, fato que não aconteceu quando o ambiente era informal, quando qualquer professor da banca ou mesmo a assistência faziam interferências em momentos inapropriados. Em consulta aos próprios alunos que defendiam suas monografias identificou-se que os mesmos achavam conveniente e "legal" o cerimonial presente no momento da defesa, pois "isso dava maior respeito ao momento".

Foi observada também entre os alunos a percepção de que se sentiam mais maduros diante da responsabilidade em apresentar um trabalho extenso ao término do curso perante uma banca composta por mais de um professor o que vem a corroborar 
como o pensamento de Bezerra (1973, p. 178) ao afirmar que os ritos da puberdade "representam a passagem de uma fase da vida para a outra".

Por fim constatou-se que o ato de "Defesa de Monografia" constitui um rito de passagem dentro da vida acadêmica que habilita o graduando a tornar-se um neograduado durante a cerimônia de Colação de Grau. Este momento culminante da vida acadêmica é uma festa de grande proporção, pois de acordo com Barros (2002, p. 39) "a festa é o que há de mais importante na vida. Resume todas as buscas humanas e simboliza a vitória sobre as penúrias e dificuldades do dia-a-dia. Sintetiza as sensibilidades, trajetórias históricas, vivências e visões de fé. A festa significa viver a liberdade." E é com este espírito que os organizadores dos cursos de graduação, traduzidos pela Coordenação do Curso, devem cuidar com esmero e dedicação aos atos de "Defesa de Monografia" iniciando o graduando nesta grande festa de conquista pessoal e coletiva.

\section{CONCLUSÃO}

Considerando que o ritual se faz presente ao longo da vida humana mesmo este homem estando inserido num contexto pós-moderno e que a Universidade, por mais antiga que seja, preserva estes ritos de passagem para valorar ainda mais seus atos, constatou-se que a ritualística presente em qualquer destes atos é valorizada pelo neoacadêmico ou pelo neo-formando.

O momento da defesa de monografia nos cursos de graduação se constitui em etapa relevante para a vida acadêmica por ser o período de coroamento da aquisição de conhecimento do acadêmico. O esforço desenvolvido, a dedicação ao estudo e, sobretudo a sensação de conseguir desenvolver um trabalho de fôlego por si só já caracteriza uma etapa especial.

É assim, responsabilidade do Curso e de seu corpo docente reverter este ato em pompa e circunstância, dando-lhe o respeito que o alunado merece por conseguir mais esta etapa da vida acadêmica, o que o habilita a participar de uma solenidade maior que é o ápice da vida acadêmica, a colação de grau superior. Não fosse assim, os próprios alunos não participariam de todos os atos de uma festa de formatura, iniciando-se pela 
aula da saudade; afixação de placa, que deixa no campus o registro perene da passagem deste aluno pela instituição; a festa propriamente dita; a missa ou culto ecumênico e, sobretudo a solenidade de colação de grau. Observa-se ao longo da caminhada acadêmica que os alunos participam voluntariamente destes atos, não fossem eles relevantes como rito de passagem não haveria adesão voluntária por parte do alunado.

À guisa de conclusão orienta-se para que o encerramento da disciplina de monografia seja realizado com todo o cerimonial e protocolo inerente ao momento, de vez que esta atitude propicia, além da seriedade e respeito impostos pelo ritual, satisfação pessoal para aqueles que participam, seja integrando a banca examinadora, seja na assistência para conhecer os resultados da pesquisa desenvolvida. Portanto, compete ao professor orientador estar à frente do processo ritualístico e aplicá-lo em todos os seus detalhes, conforme sugerido nos resultados desta pesquisa.

\section{REFERÊNCIAS BIBLIOGRÁFICAS}

BARROS, Marcelo. O Divino segredo da festa. In: PASSOS, Mauro. A festa na vida. Petrópolis, Vozes, 2002.

BEZERRA, Felte. Antropologia sociocultural. Brasília, Coordenada, 1973.

SILVA, José Solon Sales e. Curso de cerimonial público e protocolo de eventos. Brasília, Funasa, 2005, memo.

VELLOSO, Ana. Cerimonial universitário. Brasília, Universidade de Brasília, 2001.

VIANA, Flávio Benedicto. Universidade: protocolo, rito e cerimonial. São Paulo, Lúmen, 1998.

KACELNIK, Zilda. A circuncisão: o mito e o rito. Rio de Janeiro, Editora Documentário, 1974.

Recebido em: 10 de setembro de 2007

Aprovado em: 10 de outubro de 2007 